\title{
Price Forecasting Accuracy of the OECD-FAO's Agricultural Outlook and the European Commission DG AGRI's Medium-Term Agricultural Outlook Report
}

\author{
Jiř́i Pokorný, Pavel Froněk \\ Institute of Agricultural Economics and Information, Prague, Czech Republic
}

\begin{abstract}
The OECD-FAO's Agricultural Outlook and the European Commission DG AGRI's Medium-term agricultural outlook report provide price forecasts. Users of these forecasts may be interested in their accuracy. This paper measures the accuracy for values forecast for the following year. These are very accurate as regards the AO EU price of poultry, the EC outlook price of common wheat and feed barley, but not so accurate as regards the EC outlookon beef prices. In some cases, discrepancies between the forecasts follow a systematic pattern. The paper also discovers how the OECD-FAO's outlook projections for a common wheat world representative price are changing from year to year. Usually they are positively correlated, but there are certain exceptions where their correlation is significantly negative. This means that the price projections of some commodities may vary dramatically.
\end{abstract}

\section{Keywords}

Outlook, price, forecast, accuracy.

Pokorný, J. and Froněk, P. (2021) "Price Forecasting Accuracy of the OECD-FAO's Agricultural Outlook and the European Commission DG AGRI's Medium-Term Agricultural Outlook Report", AGRIS on-line Papers in Economics and Informatics, Vol. 13, No. 3, pp. 77-87. ISSN 1804-1930. DOI 10.7160/aol.2021.130308.

\section{Introduction}

The OECD-FAO's ${ }^{1} \quad$ Agricultural Outlook and the EC DG AGRI's² Medium-term agricultural outlook report provides a kind of look into the future of the agricultural economy. This includes point forecasts of prices of agricultural commodities. Forecasts might be a useful tool in planning and decision making in agricultural economics and business policy, all of which can be deduced from papers on this topic.

The data forecasting application in agriculture is evaluated ex-post in Brandt \& Bessler (1983), with positive results, or widely discussed in Allen (1994) and Bessler (2010). An ex-post evaluation of the OECD-FAO's Agricultural Outlook forecasts is in Rivera-Ferre \& Ortega-Cerdà (2010) and Holst (2010), both with not much positive results. The Rivera-Ferre \& Ortega-Cerdà (2010) article develops a theory of Stirling (1999) concerning 4 possible states of incertitude

\footnotetext{
${ }^{1}$ The Organization for Economic Co-operation and Development in cooperation with the Food and Agricultural Organization of the United Nations.

2 The Directorate-General for Agriculture and Rural Development of the European Commission.
}

and argues that such outlooks assume policy scenarios when they cannot be assumed. This is why they should not be used for policy evaluations. However, users of forecast prices from these outlooks, whether or not for policy evaluation, may be interested in their accordance with the prices that are later considered as realized. Holst (2010) shows on the price of wheat that an autoregressive estimator produces more accurate forecasts than the OECD-FAO's Agricultural Outlook.

Users of the outlook forecasts may also be interested in how much a new edition of an outlook differs from the previous one. If a price forecast differs greatly in comparison with its previous edition, the outlook model assumptions have probably changed, having a significant impact on the price. This will generally discourage dependence on medium-term forecasts of the price because of its high sensitivity to the assumptions. However, it might also mean that the model specifications for the price are incorrect or incomplete and the sensitivity is false. The potential for misspecifications in such a complex model is great, which could be a reason to prefer simple time-series estimators. 
The authors therefore measure the correspondence between price projections of different editions of the outlooks. In addition, they also apply some error decompositions that might be helpful for a user of the forecasts in accommodating the differences between projected and realized prices. To simplify the analysis, in most exercises, the authors examine only one-year-ahead forecasts.

\section{Materials and methods}

There are two main origins of the data analysed in this paper: firstly, world and EU nominal prices of selected agricultural commodities, published in yearly series of the OECD-FAO's Agricultural Outlook (OECD and FAO, 2009-2019). Selected 7 commodities that the authors of the present paper choose to analyse can be found in Table 1. Secondly, the European Commission's Mediumterm outlook report (EC, 2013-2020) yearly EU nominal prices of agricultural commodities, from which the authors choose 10 , is also to be found in Table 1 .

The OECD-FAO's Agricultural Outlook price forecasts are part of a complex process of Outlook creation, based on a recursive dynamic partial equilibrium AGLINK-COSIMO (OECD and FAO, 2015) model. In most editions of the Outlook, there is one price that is not a forecast. It is an average estimated price from three years preceding the year of publishing of the particular edition of the Outlook. The forecast prices are simply yearly prices, so they are averaged to be comparable to the 3 year realised averages.

The month of publishing is July, and the first year constituting the average begins in the succeeding January (for grains June or July). One might also download yearly realised nominal prices from https://stats.oecd.org. These are not part of the Outlook standard publication and their values vary, especially those of meats, where OECD-FAO uses different units of weight. This paper also compares this second alternative to the one with averages as to the accuracy of forecasts.

The EC DG AGRI's price forecasts have a very similar nature to those of the OECD-FAO's Agricultural Outlook, since they are based on the same AGLINK-COSIMO model, yet the overall process of forecasting is different (Enciso,et al., 2015) (Perez Dominguez, et al., 2018). The publishing month is December and this paper assesses the year following the year of publishing.

In almost all exercises, this paper assesses only single-year-ahead ${ }^{3}$ forecasts, although the forecast horizon is always up to at least 9 succeeding years. The accuracy would be higher if the forecasts were focused on the publishing year and the following year only, because then there could not be any constraints upon them to be consistent with the forecasts for the following years (the consistency is due to the recursive dynamics of the models).

A complete list of methods used for forecasting assessed prices and years in which these forecasts

\footnotetext{
3 So the assessed forecast horizon is one 3 year average (for the OECD-FAO's Outlook) or one year (for the EC's Outlook). For computing the averages, forecasts for the 3 succeeding years are needed.
}

\begin{tabular}{|l|l|l|l|}
\hline Referred to as & Full description & Unit & Source \\
\hline AO wheat & $\begin{array}{l}\text { No. 2 hard red winter wheat, ordinary protein, USA } \\
\text { f.o.b. Gulf Ports (June/May). }\end{array}$ & USD/t & OECD-FAO Agricultural Outlook \\
\hline AO corn & $\begin{array}{l}\text { No. 2 yellow corn, USA f.o.b. Gulf Ports (September/ } \\
\text { August). }\end{array}$ & USD/t & OECD-FAO Agricultural Outlook \\
\hline AO EU beef & EU average beef producer price. & USD/100 kg dw & OECD-FAO Agricultural Outlook \\
\hline AO EU pigmeat & EU average pig meat producer price. & USD/100 kg dw & OECD-FAO Agricultural Outlook \\
\hline AO EU poultry & Poultry meat EU average producer price. & USD/100 kg rtc & OECD-FAO Agricultural Outlook \\
\hline AO butter & F.o.b. export price, butter, 82\% butterfat, Oceania. & USD/100 kg & OECD-FAO Agricultural Outlook \\
\hline AO cheese & $\begin{array}{l}\text { F.o.b. export price, cheddar cheese, 39\% moisture, } \\
\text { Oceania. }\end{array}$ & USD/100 kg & OECD-FAO Agricultural Outlook \\
\hline EU wheat & $\begin{array}{l}\text { Common wheat (breadmaking quality) price (July/ } \\
\text { June) }\end{array}$ & EUR/t & EC Medium-term outlook report \\
\hline EU barley & Feed barley price (July/June) & EUR/t & EC Medium-term outlook report \\
\hline EU maize & Feed maize price (July/June) & EUR/t & EC Medium-term outlook report \\
\hline
\end{tabular}




\begin{tabular}{|l|l|l|l|}
\hline Referred to as & Full description & Unit & Source \\
\hline EU sugar & $\begin{array}{l}\text { Sugar (white sugar equivalent) price (October/ } \\
\text { September) }\end{array}$ & EUR/t & EC Medium-term outlook report \\
\hline EU beef & Beef (Young bulls R3) meat price & EUR/t c. w. e. & EC Medium-term outlook report \\
\hline EU pigmeat & Pig (Class E) meat price & EUR/t c. w. e. & EC Medium-term outlook report \\
\hline EU poultry & Poultry (Chicken) meat price & EUR/t c. w. e. & EC Medium-term outlook report \\
\hline EU milk & Milk (farm gate, real fat content) price & EUR/t & EC Medium-term outlook report \\
\hline EU butter & EU-15 Butter price & EUR/t & EC Medium-term outlook report \\
\hline EU cheese & EU Cheddar Cheese price & EUR/t & EC Medium-term outlook report \\
\hline
\end{tabular}

Source: own processing

Table 1: List of commodities whose price forecasts are assessed (continuation).

\begin{tabular}{|c|c|c|c|c|c|c|c|c|}
\hline & 2009 & 2010 & 2011 & 2012 & 2013 & 2014 & 2015 & 2016 \\
\hline AO wheat & \multicolumn{8}{|c|}{$\mathrm{A}-\mathrm{C}$} \\
\hline $\mathrm{AO}$ corn & \multicolumn{8}{|c|}{$\mathrm{A}-\mathrm{C}$} \\
\hline AO butter & & \multicolumn{7}{|c|}{ A-C } \\
\hline AO cheese & & \multicolumn{7}{|c|}{ A-C } \\
\hline AO EU commodities & & & \multicolumn{6}{|c|}{$\mathrm{A}-\mathrm{C}$} \\
\hline EU commodities & & & & & \multicolumn{4}{|c|}{ EC A-C } \\
\hline
\end{tabular}

Note: AO EU commodities Those of table 1 with name starting with "AO EU" (meats only). EU commodities Those of table 1 with name starting with "EU".

A-C Years in which the AGLINK-COSIMO model was applied.

EC A-C Years in which the European Commission DG AGRI's version of AGLINK-COSIMO model was applied.

Realized prices as published by the EC (EU commodities) are the same as those published in the OECD-FAO Outlook (AO EU commodities), but forecasts are different between these two Outlooks. AO commodities are also assessed in another setting with different periods (Table 5).

Source: own processing

Table 2: List of commodities and corresponding methods and periods.

were made is in Table 2.

For the evaluation of time series forecasts, there are many possible measures. Hyndman and Koehler (2006) explain why to avoid choosing some of them. They recommend the MASE (Mean Absolute Scaled Error). There is also the Theil's UII (Theil's U2) coefficient (Theil, 1966, as cited in Bliemel, 1973), also referred to as the Relative Root Mean Squared Error (RelRMSE) (De Gooijer and Hyndman, 2006), which is similar to the MASE. The UII penalizes large errors more and when applied on the same forecast it can be either higher or lower, but in the exercise in the present paper both measures lead to very similar results. Since the formula for the UII (Equation 1) is simpler, only results for the UII are presented. It is calculated for each commodity separately.

t... time (year of the time series of a particular commodity),

$n$... Number of forecasts (of 1 year long horizon) that we evaluate.
$Y_{j} \ldots \quad$ The average realized price over the period: $\{t ; t+1 ; t+2\} \quad$ where $t=j$ (in the case of OECD and FAO Outlooks) or the realized price at time $t$ (in the case of EC Outlooks).

$\hat{Y}_{j} \ldots$ The average of forecasted prices for the period $\{t ; t+1 ; t+2\}$ where $t=j$ (in the case of OECD and FAO Outlooks) or the forecasted price for time $t$ (in the case of EC Outlooks).

l... Number of periods back to the latest time $i$-l, for which $Y_{i-l}$ is known at the time of predicting $Y ; l=4$ in the case of OECD and FAO Outlooks and $l=2$ in the case of EC Outlooks.

$U I I=\sqrt{\frac{\sum_{t=1}^{n}\left(\hat{Y}_{t}-Y_{t}\right)^{2}}{\sum_{t=1}^{n}\left(Y_{t}-Y_{t-l}\right)^{2}}}$

Relative errors are scale independent, so they are more easily comparable across commodities. However, each time series is specific not only due 
to its scale, but also to its length, and variance. The UII might be interpreted as a measure of errors of a sequence of forecasts relative to a corresponding sequence of "naïve" forecasts (the latter is in the denominator of the equation). These "naïve" forecasts predict for time $t$ the same price as is the price at time $t-l$. They are comprised of the last whole year available, so $l$ is equal to 2 for $\mathrm{EU}$ (EC's outlook) prices. But for the AO and AO EU prices, the last available price at time $t$ is the average price over $t-3, t-2$, and $t-1$.

Davydenko and Fildes (2016) point out an undesirable property of the MASE, which is that it overrates the accuracy of a benchmark forecasting method because of the arithmetic mean used in its formula. However, in the present paper, the UII is applied in such a way that it does not overrate the accuracy of the benchmark forecasting method. For example, if the UII is 0.5 , it should be interpreted as the benchmark (naive) forecast having approximately twice as large an error as the nonnaive forecast. This is because 1 (which is the benchmark UII) divided by 0.5 equals 2 . On the other hand, if the benchmark is twice as accurate as the nonnaive forecast, the UII is approximately equal to 2 . Therefore, for the interpretation of the UII values between 0 and 1 (the UII is never lower than 0): number 1 should be divided by the UII, and the resulting number shows how many times larger error the benchmark has. However, for the interpretation of the UII values greater than 1: without any further computation, the number directly states how many times more accurate the benchmark is. To avoid the undesirable overrating when computing an arithmetic average UII, this paper applies a transformation on the UII if it is lower than 1 (Equation 2):

$\widetilde{U I I}=\left\{\begin{aligned} U I I, & U I I \geq 1 \\ 2-\frac{1}{U I I}, & U I I<1\end{aligned}\right.$

AvgUII $=$ Arithmetic average $(\widetilde{U I I})$.

As Davydenko and Fildes (2016) also note, the arithmetic mean is severely influenced by extreme cases. The transformation in Equation 2 does not prevent this problem. Nevertheless, in the present paper, there are no extreme cases among the selected forecasts.

The UII is a measure which does not provide information on the probability that the assessed forecast is significantly different from the naïve benchmark forecast. Diebold and Mariano (1995) suggests 3 tests to provide such information.
The second test (the Sign test) gives at least some idea even if number of observations is very low. The other two tests would be more difficult to compute and interpret. In the present paper, probabilities are presented that the Sign test statistic states its computed value assuming the forecasts are equally accurate. A null hypothesis that they are equally accurate ${ }^{4}$ is rejected at the $10 \%$ level of significance if the statistic is lower than 0.1 .

To discover the nature of the forecast errors, this paper applies an MSE decomposition formula (Cipra, 2013) (Equation 3):

MSE... Mean Squared Error,

$\sigma \ldots \quad$ standard deviation,

$\rho . . \quad$ Pearson's correlation coefficient,

$$
\begin{aligned}
M S E & =\sum_{t=1}^{n} \frac{\left(\hat{Y}_{t}-Y_{t}\right)^{2}}{n}=\left(\sum_{t=1}^{n} \frac{\hat{Y}_{t}}{n}-\sum_{i=1}^{n} \frac{Y_{t}}{n}\right)^{2} \\
& +\left(\sigma_{\hat{Y}}-\sigma_{Y}\right)^{2}+2\left(1-\rho_{\hat{Y} Y}\right) \sigma_{\hat{Y}} \sigma_{Y} \\
& =M S E_{\text {bias }}+M S E_{\sigma}+M S E_{\varepsilon} .
\end{aligned}
$$

The MSE is also sometimes used for assessing the inaccuracy of forecasts, but here just for the decomposition. The three main parentheses on the right side of Equation 3 divided each by the sum of the three then count to 1 and are called "the bias proportion", "the variance proportion", and "the covariance proportion". The numerator of the bias proportion represents the distance between means of forecast and realised prices, the numerator of the variance proportion represents the difference between the variances of forecast and realized prices, and the numerator of the remaining part indicates a non-systematic error. A forecast can be considered optimal according to this decomposition approach if its covariance proportion (MSEE/MSE) is $100 \%$ (the other two proportions are $0 \%$ ).

Due to comments by Ahlburg (1984), the authors also apply a decomposition formula called "Theil's decomposition", which is a function of growth indexes rather than absolute values and includes correlation in the second component in addition to the third one (Equation 4):

$$
\begin{aligned}
\widehat{Y}^{\prime}{ }_{t} & =\left\{\frac{\hat{Y}_{t}}{Y_{t-1}}\right\}_{t=1, \ldots, n} \\
Y^{\prime}{ }_{t} & =\left\{\frac{Y_{t}}{Y_{t-1}}\right\}_{t=1, \ldots, n}
\end{aligned}
$$

${ }^{4}$ This equality means that the median of differences between these forecasts' absolute errors equals zero. 


$$
\begin{aligned}
& M S E^{\prime}=\sum_{t=1}^{n} \frac{\left(\widehat{Y}_{t}{ }_{t}-Y^{\prime}{ }_{t}\right)^{2}}{n}=\left(\sum_{t=1}^{n} \frac{\left(\widehat{Y}^{\prime}{ }_{t}\right)}{n}-\sum_{t=1}^{n} \frac{\left(Y^{\prime}{ }_{t}\right)}{n}\right)^{2} \\
& +\left(\sigma_{\hat{Y}^{\prime}{ }_{t}}-\rho_{\hat{Y}^{\prime}{ }_{t} Y^{\prime}{ }_{t}} \sigma_{Y^{\prime}{ }_{t}}\right)^{2}+\left(1-\rho_{\hat{Y}^{\prime}{ }_{t} Y^{\prime}{ }_{t}}^{2}\right){\sigma_{Y^{\prime}{ }_{t}}^{2}}^{2} \\
& =M S E_{\text {bias }}^{\prime}+M S E_{\text {regression }}^{\prime}+M S E_{\text {Theils } \varepsilon}^{\prime} \text {. }
\end{aligned}
$$

The presence of the correlation coefficient in the second component in Theil's version (Equation 4) often results in higher values of the second component compared to the first version of the decomposition (Equation 3). The three respective components, dividing each by the sum of the three, are called "the bias proportion" (different from "the bias proportion" of Equation 3), "the regression proportion", and "the disturbance proportion". The word "regression" recalls the possibility of using a linear regression model for an adjustment of the forecast. This adjustment eradicates the bias and regression proportions of the MSE'. The regression proportion arises from systematic under or over estimation of the slope of the relationship between a realised series and its forecast (Theil, 1971, as cited in Ahlburg, 1984). However, the adjustment is exogenous to the AGLINK-COSIMO model, so it will not be compatible with the model equilibrium.

To avoid misleadings, the two types of decomposition had better not be compared across commodities without accounting for the sum of the three proportions being variable across commodities. This is because the MSE is scale dependent.
To differentiate between the case when forecasts are generally higher than realized prices and the opposite case, the second column in Table 3 signifies whether and how much the sum of forecasts of prices of a commodity is higher or lower than the sum of its realised prices.

To measure how the price forecasts of the OECD and FAO's Agricultural Outlook are consistent, 6 editions are compared, from that published in 2011 to the one published in 2016. Each of these include forecasts of the price of common wheat (in Table 1 the AO wheat) for at least the period 2016-20205. Pairs of outlooks are compared using paired tests on the equivalence of mean values, and the Pearson's and the Spearman's correlation coefficients. The Spearman's correlation coefficient is more robust than the Pearson's, but requires a transformation of the time series (Huber, 1981).

\section{Results and discussion}

For each commodity, the percentage difference between the sum of forecasts and of realisations, the assessment indicator UII, the Sign test probability, and the two versions of the MSE decomposition are calculated from forecasts made within the periods stated in Table 2, and the results are summarized in Table 3.

\footnotetext{
${ }^{5}$ Therefore, their forecast horizons range from 0 at minimum to 9 years at maximum succeeding the year of publication. The 0 forecast horizon means the projection for the year 2016 published at the same
} year.

\begin{tabular}{|l|c|c|c|c|c|c|}
\hline \multirow{2}{*}{ Commodity } & \multirow{2}{*}{$\left(\sum \hat{\mathrm{Y}}_{\mathrm{t}} / \sum \mathrm{Y}_{\mathrm{t}}\right)-1$} & \multirow{2}{*}{$\mathrm{UII}$} & \multirow{2}{*}{$\begin{array}{c}\text { Sign test } \\
\text { probability }\end{array}$} & \multicolumn{2}{|c|}{ MSE proportions } & MSE' regression proportion \\
\cline { 5 - 6 } & & & Bias & Vrowth indexes \\
\hline AO wheat & $-8 \%$ & 1.0 & 0.273 & $10 \%$ & $10 \%$ & $73 \%$ \\
\hline AO corn & $-2 \%$ & 0.8 & 0.218 & $0 \%$ & $15 \%$ & $80 \%$ \\
\hline AO EU beef & $8 \%$ & 1.4 & 0.235 & $12 \%$ & $23 \%$ & $81 \%$ \\
\hline AO EU pigmeat & $26 \%$ & 1.4 & 0.235 & $69 \%$ & $0 \%$ & $20 \%$ \\
\hline AO EU poultry & $7 \%$ & 0.8 & 0.093 & $25 \%$ & $0 \%$ & $46 \%$ \\
\hline AO butter & $-15 \%$ & 1.3 & 0.165 & $39 \%$ & $2 \%$ & $43 \%$ \\
\hline AO cheese & $-2 \%$ & 1.3 & 0.273 & $1 \%$ & $2 \%$ & $86 \%$ \\
\hline EU wheat & $4 \%$ & 0.2 & 0.062 & $61 \%$ & $1 \%$ & $0 \%$ \\
\hline EU fbarley & $-2 \%$ & 0.5 & 0.062 & $3 \%$ & $1 \%$ & $69 \%$ \\
\hline EU maize & $-2 \%$ & 0.2 & 0.376 & $12 \%$ & $1 \%$ & $2 \%$ \\
\hline EU sugar & $17 \%$ & 0.6 & 0.250 & $62 \%$ & $8 \%$ & $3 \%$ \\
\hline EU beef & $-6 \%$ & 4.2 & 0.250 & $39 \%$ & $24 \%$ & $58 \%$ \\
\hline
\end{tabular}

Source: own processing 


\begin{tabular}{|l|c|c|c|c|c|c|}
\hline \multirow{2}{*}{ Commodity } & \multirow{2}{*}{$\left(\sum \hat{\mathrm{Y}}_{\mathrm{t}} / \sum \mathrm{Y}_{\mathrm{t}}\right)-1$} & \multirow{2}{*}{ UII } & \multirow{2}{*}{$\begin{array}{c}\text { Sign test } \\
\text { probability }\end{array}$} & \multicolumn{2}{|c|}{ MSE proportions } & \multirow{2}{*}{$\begin{array}{c}\text { MSE' regression proportion } \\
\text { of growth indexes }\end{array}$} \\
& & & & Bias & Variance & $23 \%$ \\
\hline EU pigmeat & $10 \%$ & 1.0 & 0.250 & $38 \%$ & $3 \%$ & $12 \%$ \\
\hline EU poultry & $-4 \%$ & 1.2 & 0.376 & $69 \%$ & $5 \%$ & $23 \%$ \\
\hline EU milk & $-1 \%$ & 0.5 & 0.376 & $1 \%$ & $54 \%$ & $0 \%$ \\
\hline EU butter & $-8 \%$ & 0.7 & 0.250 & $12 \%$ & $38 \%$ & $15 \%$ \\
\hline EU cheese & $4 \%$ & 0.7 & 0.250 & $7 \%$ & $24 \%$ & 0 \\
\hline
\end{tabular}

Source: own processing

Table 3: Results by commodity (continuation).

The AO wheat 3-year-average price is forecast much lower in most years of the selected period and the sum of forecasts is $8 \%$ lower than the sum of realisations (Table 3). The UII is equal to 1.0 , so the A-C forecasts in average have the same errors as the naïve no change forecasts. The sign test probability is not low enough to reject this hypothesis. The regression proportion is high, which means that a more effective forecast could be made using the procedure that Theil suggests.

AO corn 3-year-average price forecasts are more accurate than the naïve no change forecasts, but the hypotheses that the accuracy is the same cannot be rejected. Its MSE decompositions are similar to those of the $\mathrm{AO}$ wheat price. In this way, conclusions can be made from Table 3 for each commodity. However, it should be emphasized again that the results can be compared between commodities only if differences between the sample sizes (Table 2) and differences between the total MSEs (Equations 3 and 4 for various $Y$ ) are taken into account.

Rivera-Ferre \& Ortega-Cerdà (2010) use the Mean Absolute Percentage Error measure on the AO published between 1999-2008 for wheat, corn, oilseed, oilseed meal, and rice prices. Corn has the lowest MAPE, $15 \%$, while wheat has $17-18 \%$. In the sample in the present paper (Table 1), corn has $28 \%$ and wheat $23 \%$ MAPE, so the discrepancy increased with the newer sample. Rivera-Ferre \& Ortega-Cerdà also discovered that the MAPE generally increases with the length of the horizon.

Holst (2010) calculates the UII for AO wheat from AO published between 1995-2006, which amounts to 1.0 , the same as in the present paper. Interestingly, if the author drops the 2007/2008 observation, which was an extreme, the UII for the 1-year horizon rises to 1.1, although for the other horizons it falls more significantly. There are also two more models in his comparison - the one developed by the Food and Agricultural Policy Research Institute (FAPRI), and one simple autoregressive developed by him specifically for this purpose. The FAPRI has results similar to the OECD-FAO. The AR estimator has similar results in its simplest version, with a potential to improve it by adding some exogenous predictors.

Even though the UII ranges from high to low values, there are only three cases (AO EU poultry, EU wheat, and EU fbarley) where an outlook forecast is significantly better or worse than the naïve no-change forecast (at the 10\% level of significance). In all three, the outlook forecast is more accurate, so overall there is no commodity in which the outlook forecast is significantly worse. The highest UII is for EU beef, where most of the error is systematic. Beef price forecasts (both EU and AO EU) have exceptionally bad fits and exceptionally high regression proportions, which suggests using Theil's correction procedure. This procedure might be especially promising with the AO commodities. In general, this should be considered when the percentage difference is simultaneously large, the UII greater than 1, and the regression proportion is high. If the regression proportion is low, but the percentage difference and the bias proportion are large (such as for EU sugar), a simple adjustment for the percentage difference would be more suitable. If the variance proportion is high (EU milk), the analysis of variance can be helpful. If the regression, bias, and variance proportions are all low (EU maize, EU cheese), corrections are less justified.

The second column of Table 3 shows some exceptional patterns. The AO commodities have underestimated prices (minus signs), which could however just be due to evaluating longer periods than for the AO EU commodities, which have overestimated prices. Forecasts made in 2009 and 2010 for AO commodities are exceptionally underestimated, which explains this pattern. On the other hand, EU commodities, having every one the same four-year period of publishing which 
mostly overlaps those of the AO and AO EU, have forecast prices both higher and lower than they realise.

Table 4 partly repeats the UII results from Table 3 (3-year averages column) and compares them to UIIs computed from 1-year data (the realizations are taken from the http://stats.oecd.org website). AO EU commodities (meats) realisations differ to a great extent between the Outlook publication and the website, so the comparison cannot be made.

The comparison of Table 4 is flawed in that the sample lengths are not the same. Still, it generally gives an example that the second variant lead to slightly better results. This is because the horizon is always shorter than in the first variant. At any rate, the decision to primarily use the 3-year averages instead of the data from the website has not affected the results for AO commodities very much.

To summarize for each commodity, 7 indicators are computed. From all 17 commodities, 9 have prices forecast more accurately than they would have if the specified naïve no change forecast was used instead. As far as the 7 selected commodities from the OECD\&FAO's Agricultural Outlook (method A C) are concerned, the mean UII (Equation 2) is 1.1, and there are 2 with higher accuracy compared to the naïve forecast. For the EU's Medium term agricultural outlook (method EC A C), there are 10 selected commodities. Their mean UII is 0.2 . 7 are forecast more accurately than using the naïve method. That is much lower than for the OECD\&FAO's Agricultural Outlook, partly as a consequence of higher lag 1 in Equation 1.

These results do not mean that the 8 commodity forecasts that do not outperform the naïve forecasts should be abandoned. They have important qualities that the measures used in the evaluation in this paper do not capture. Firstly, the forecasts are part of a structural model or reasoning which the naïve forecasts cannot match. Secondly, the accuracy of forecasts could be improved by calibration of the forecasting model, which is not possible with the naïve forecasts. Thirdly, the time series used in the analysis in this paper are very short, so there is a high probability that by adding new observations the results will change a bit.

The Theil's correction procedure is only feasible for an external user of the outlooks when realized prices are available for the period of interest. This means for example that in July 2019, it can be applied to correct a forecast of $\mathrm{AO}$ and $\mathrm{AO}$ EU commodities 2020-22 average prices using the errors of the ex-post-forecasts made in periods described in Table 2. In December 2019, it can be similarly applied to correct a forecast of EU commodities 2020 prices. The periods described in Table 2 are those that the results (Table 3 and 4) and discussion in this paper are based upon, but a selection of different sample periods is possible. The correction procedure can be recalculated on a longer sample when new editions of the outlooks are available.

OECD does not publish its own ex post evaluation of the AGLINK-COSIMO price forecasts, nor does the European Commission. Nevertheless, OECD (2017) refers to a stochastic analysis of the OECD\&FAO's Agricultural Outlook. It is based on 1,000 simulations with varying selected macroeconomic and yield parameters, which provide ex ante information about how large the price forecast error will be in $80 \%$ of cases. In the example presented, a maize price forecast has an asymmetric distribution - there is higher risk of a large positive than a large negative price movement. Such skewness is characteristic for the other $\mathrm{AO}$ and $\mathrm{AO}$ EU commodities as well. These results can be useful when operating with the A-C price forecasts.

Table 5 shows that there are significant negative correlation coefficients between the editions. Given that the methodology of the Outlook does not

\begin{tabular}{|l|c|c|c|c|}
\hline \multirow{2}{*}{ Commodity } & \multicolumn{2}{|c|}{ 3-year averages } & \multicolumn{2}{|c|}{ 1-year } \\
\cline { 2 - 3 } & UII & sample length & UII & sample length \\
\hline AO wheat & 1.0 & \multirow{2}{*}{$2009-2016$} & 1.0 & $2006-2016$ \\
\hline AO corn & 0.8 & & 0.7 & $2007-2016$ \\
\hline AO butter & 1.3 & \multirow{2}{*}{$2010-2016$} & 1.3 & $2010-2016$ \\
\hline AO cheese & 1.3 & & 0.9 & \\
\hline
\end{tabular}

Note: Computation with 1-year data allows for a longer sample Source: own processing

Table 4: Comparison of 3-year averages with yearly data. 


\begin{tabular}{|c|c|c|c|c|c|c|c|c|c|c|c|}
\hline & & \multicolumn{2}{|c|}{ A (2011) } & \multicolumn{2}{|c|}{ B (2012) } & \multicolumn{2}{|c|}{$\mathrm{C}(2013)$} & \multicolumn{2}{|c|}{ D (2014) } & \multicolumn{2}{|c|}{ E (2015) } \\
\hline & & Cor & 2-side $\mathrm{pr}$ & Cor & 2-side pr & Cor & 2-side pr & Cor & 2-side pr & Cor & 2-side pr \\
\hline \multirow[t]{2}{*}{ B } & Pear & 0.46 & 0.43 & & & & & & & & \\
\hline & Sprm & 0.00 & 1.00 & & & & & & & & \\
\hline \multirow[t]{2}{*}{$\mathrm{C}$} & Pear & 0.21 & 0.73 & 0.96 & $* * * 0.01$ & & & & & & \\
\hline & Sprm & -0.40 & 0.50 & 0.90 & $* * 0.04$ & & & & & & \\
\hline \multirow[t]{2}{*}{$\mathrm{D}$} & Pear & 0.36 & 0.56 & 0.98 & $* * * 0.00$ & 0.97 & $* * * 0.01$ & & & & \\
\hline & Sprm & 0.10 & 0.87 & 0.90 & $* * 0.04$ & 0.80 & 0.10 & & & & \\
\hline \multirow[t]{2}{*}{ E } & Pear & 0.03 & 0.96 & 0.81 & $* 0.09$ & 0.90 & $* * 0.04$ & 0.80 & 0.10 & & \\
\hline & Sprm & -0.40 & 0.50 & 0.90 & $* * 0.04$ & 1.00 & $* * * 0.00$ & 0.80 & 0.10 & & \\
\hline \multirow[t]{2}{*}{$\mathrm{F}$} & Pear & -0.83 & $* 0.08$ & -0.10 & 0.87 & 0.15 & 0.81 & -0.08 & 0.90 & 0.43 & 0.47 \\
\hline & Sprm & -0.80 & 0.10 & 0.30 & 0.62 & 0.50 & 0.39 & 0.10 & 0.87 & 0.50 & 0.39 \\
\hline
\end{tabular}

Note: The year in parenthesis is the publishing year of the edition. Pear assumes normality, Sprm does not. Normality is not tested due to small number of observations ( $5 \mathrm{obs}$.). The null hypothesis is that the correlation coefficient is zero. In the 2 -side pr columns, ${ }^{* *}$ means significance at the $5 \%$ level $(*$ at $10 \%, * * *$ at $1 \%$ ). Rejection is at the $5 \%$ level of significance Source: own processing

Table 5: Correlation coefficients of prices of common wheat from 6 editions of the OECD and FAO's Agricultural Outlook.

basically change, it is interesting to find a change in a projected trend from positive to negative or vice versa. Such a change is especially true for the pair A and F. The coefficients suggest that the break point in the series of editions of the Outlooks happens between E (2015) and $F$ (2016). A change in projection cannot also be rejected between $\mathrm{A}$ and $\mathrm{B}$. Otherwise, the dynamics of projections does not change significantly from one edition to the next.

The correlation coefficients prove that the price forecasts really are sensitive on the parameters of the model. It is not clear whether this sensitivity is based on real economic determinants or not. Von Lampe et al. (2014) show that there are many factors that influence the price forecast. The sole existence of various definitions of the representative world price in models other than the AGLINK -COSIMO gives reason to assume some incertitude regarding the outlooks. Out of the 10 global models for agriculture examined in the article, 3 forecast an overall real price for agriculture to be declining until 2030 whereas the others forecast it to be mostly rising. There are also large regional differences according to these models. Using the forecasts in some applications might also require setting some international financial exchange parameters, which each model computes in its own way.

\section{Conclusion}

The spectrum of results of evaluation of using the OECD\&FAO's and EC DG AGRI's outlooks as forecasts of world and EU prices of agricultural commodities on one year horizon is wide for each of the selected measures. There are no two commodities that can be shown to have the same overall results.

The forecasts may certainly be used as regards the AO EU price of poultry, the EU price of common wheat and feed barley, since it is statistically proven here that they are better than the naïve no-change estimator. For other commodities, the results only help in a decision where many other factors should be taken into account. These factors include the possibility of using the forecasts of another models or estimators, the existence of more possible definitions of the representative prices, or the sensitivity of the forecasts on model parameters. Different models sometimes produce substantially different forecasts.

The sensitivity of price forecasts is especially a problem for periods when there are changes in policy. Forecasting accuracy depends a lot on the choice of the sample period. It also depends on the length of the horizon - for the one-yearahead forecasts of prices of some commodities (EC outlook beef price), the accuracy is exceptionally low. For longer forecasting horizons, some studies show that their potential is greater. As for the future editions of the OECD-FAO and the EC outlooks, there is a potential for the accuracy to become higher relative to simple time-series estimators due to the enlargement of databases.

Regarding the OECD-FAO's Agricultural Outlook, 
this paper shows that projections are changing from year to year publication. Usually they are positively correlated, but there are some exceptions where the correlation is significantly negative. That means that projections of some commodities may vary dramatically.

In some cases, the authors recommend considering an adjustment of the outlook forecast on the year after the year of publication. This adjustment could be based on computing forecast errors of forecasts from previous editions of the outlook. If these errors have a systematic pattern, there is a chance to obtain a more accurate forecast for one particular commodity in one particular year. Such forecasts will not be in the original structural relation to other variables of the outlook nor to the following 8 years of the outlook projection.

\section{Acknowledgements}

Supported by the Ministry of Agriculture of the Czech Republic, institutional support MZERO0918.

The corresponding author contributed with the text and the calculations except for those calculations concerning the correlations between the OECDFAO Outlooks of various years of publication.

The authors thank the Institute of Agricultural Economics and Information for support, the authors of the outlooks for their data, Markéta Bříšková for helping with obtaining the OECD-FAO data, the Czech University of Life Sciences Prague for access to scientific literature and the Writefull application (add-on for MS Word), and reviewers of the paper for their feedback.

Corresponding authors

Jiř́ Pokorný, M.A.

Institute of Agricultural Economics and Information, Mánesova 1453/75

12000 Prague 2, Czech Republic

Phone: +420222000 317,E-mail: pokorny.jiri@uzei.cz

Orcid Number 0000-0002-8278-1562

\section{References}

[1] Ahlburg, D. A. (1984) "Forecast evaluation and improvement using Theil's decomposition", Journal of Forecasting, Vol. 3, No. 3, pp. 345-351. E-ISSN 1099-131X, ISSN 0277-6693. DOI 10.1002/for.3980030313.

[2] Allen, P. G. (1994) "Economic forecasting in agriculture", International Journal of Forecasting, Vol. 10, No. 1, pp. 81-135. ISSN 0169-2070. DOI 10.1016/0169-2070(94)90052-3.

[3] Bessler, D. A., Dorfman, J. H., Holt, M. T. and LaFrance, J. T.(2010) "Econometric Developments in Agricultural and Resource Economics: The First 100 Years", American Journal of Agricultural Economics, Vol. 92, No. 2, pp. 571-589. E-ISSN 1467-8276, ISSN 0002-9092. DOI 10.1093/ajae/aaq010.

[4] Bliemel, F. (1973) "Theil's forecast accuracy coefficient: A clarification", Journal of Marketing Research, Vol. 10, No. 4, pp. 444-446. ISSN 0022-2437. DOI 10.2307/3149394.

[5] Brandt, J. A. and Bessler, D. A. (1983) "Price Forecasting and Evaluation: An Application in Agriculture", Journal of Forecasting, Vol. 2, No. 3, pp. 237-248. ISSN 0277-6693. DOI 10.1002/for.3980020306.

[6] Cipra, T. (2013) "Finanční ekonometrie", Ekopress, s. r. o., p. 245. ISBN 978-80-86929-93-4. (In Czech).

[7] Davydenko, A. and Fildes, R. (2016) "Forecast Error Measures: Critical Review and Practical Recommendations", In: Business Forecasting: Practical Problems and Solutions, John Wiley \& Sons Inc., pp. 238-249. ISBN 978-1-11922829-5.

[8] De Gooijer, J. G. and Hyndman, R. J. (2006) "25 years of time series forecasting", International Journal of Forecasting, Vol. 22, No. 3, pp. 443-473. ISSN 0169-2070. DOI 10.1016/j.ijforecast.2006.01.001. 
[9] Diebold, F. X. and Mariano, R. S. (1995) "Comparing Predictive Accuracy", Journal of Business \& Economic Statistics, Vol. 13, No. 3, pp. 253-263. ISSN 0735-0015. DOI 10.1080/07350015.1995.10524599.

[10] EC (2018) "EU agricultural outlook for markets and income", 2018-2029, European Commission, DG Agriculture and Rural Development, Brussels, pp. 107-120.

[11] EC (2019) "EU agricultural outlook for markets and income", 2019-2030, European Commission, DG Agriculture and Rural Development, Brussels, pp. 75-86.

[12] Enciso, S. R. A., Dominguez, I. P., Santini, F. and Hélaine, S. (2015) "Documentation of the European Comission's EU module of the Aglink-Cosimo modelling system", JRC Science and Policy Reports, pp. 7-10. ISBN 978-92-79-46196-5. DOI 10.2791/675854.

[13] European Commission (2013) "EU agricultural outlook for agricultural markets and income", 20132024, European Commission, DG Agriculture and Rural Development, Brussels, pp. 66-80.

[14] European Union (2014) "EU agricultural outlook, Prospects for agricultural markets and income in the EU", 2014-2025, European Commission, DG Agriculture and Rural Development, Brussels, pp. 66-80.

[15] European Union (2015) "EU agricultural outlook, Prospects for agricultural markets and income", 2015-2026, European Commission, DG Agriculture and Rural Development, Brussels, pp. 73-82.

[16] European Union (2016) "EU agricultural outlook for agricultural markets and income", 2016-2027, European Commission, DG Agriculture and Rural Development, Brussels, pp. 69-79.

[17] European Union (2017) "EU agricultural outlook for agricultural markets and income", 2017-2028, European Commission, DG Agriculture and Rural Development, Brussels, pp. 82-93.

[18] Rivera-Ferre, M. G. and Ortega-Cerdà, M. (2010) "Large discrepancies between agricultural outlook predictions and real trends: ignorance or uncertainty?", ISDA 2010, Jun 2010, Montpellier, France. 10 p. [Online]. Available: https://hal.archives-ouvertes.fr/hal-00522721v2 [Accessed 25 Mar. 2020].

[19] Franses, P. H. (2016) "A note on the mean absolute scaled error", International Journal of Forecasting, Vol. 32, No. 1, pp. 20-22. ISSN 0169-2070, DOI 10.1016/j.ijforecast.2015.03.008.

[20] Holst, C. (2010) "How predictable are prices of agricultural commodities? The possibilities and constraints of forecasting wheat prices", IAMO Forum 2010, Halle (Saale), June 16 - 18, 2010: Institutions in Transition - Challenges for New Modes of Governance, Leibniz-Institut für Agrarentwicklung in Mittel- und Osteuropa (IAMO), Halle (Saale). [Online]. Available: http://hdl.handle.net/10419/52717 [Accessed 25 Mar. 2020].

[21] Huber, P. J. (1981) "Robust Statistics", Wiley. ISBN 9780471418054. DOI 10.1002/0471725250.

[22] Hyndman, R. J. and Koehler, A. B. (2006) "Another look at measures of forecast accuracy", International Journal Of Forecasting, Vol. 22, No. 4, pp. 679-688. ISSN 0169-2070. DOI 10.1016/j.ijforecast.2006.03.001.

[23] von Lampe, M., Willenbockel, D., Ahammad, H., Blanc, E., Cai, Y., Calvin, K., Fujimori, S., Hasegawa, T., Havlik, P., Heyhoe, E., Kyle, P., Lotze-Campen, H., Mason d'Croz, D., Nelson, G. C., Sands, R. D., Schmitz, C., Tabeau, A., Valin, H., van der Mensbrugghe, D. and van Meijl, H. (2014) "Why do global long-term scenarios for agriculture differ? An overview of the AgMIP Global Economic Model Intercomparison", Agricultural Economics, Vol. 45, No. 1, pp. 3-20. ISSN 0169-5150. DOI 10.1111/agec.12086.

[24] OECD (2017) "Stochastic analysis of the OECD-FAO Agricultural Outlook 2017-2026". [Online]. Available: http://www.agri-outlook.org/relatedwork/Stochastic-Analysis-Agricultural-Outlook.pdf [Accessed 21 Mar. 2019].

[25] OECD (2018) "OECD.Stat", Dataset: OECD-FAO Agricultural Outlook. [Online]. Available: https://stats.oecd.org [Accessed in 2018-2019]. 
[26] OECD and FAO (2015) "Aglink-Cosimo Model Documentation". [Online]. Available: http://www.agri-outlook.org/about/Aglink-Cosimo-model-documentation-2015.pdf [Accessed: 2 Feb. 2018].

[27] OECD/FAO (2015) "OECD-FAO Agricultural Outlook" OECD Agriculture statistics (database). DOI 10.1787/agr-outl-data-en.

[28] OECD/FAO (2016) "OECD-FAO Agricultural Outlook" OECD Agriculture statistics (database). DOI 10.1787/agr-outl-data-en.

[29] OECD/FAO (2017) "OECD-FAO Agricultural Outlook" OECD Agriculture statistics (database). DOI 10.1787/agr-outl-data-en.

[30] OECD/FAO (2018) "OECD-FAO Agricultural Outlook" OECD Agriculture statistics (database). DOI 10.1787/agr-outl-data-en.

[31] OECD and FAO (2009-2019) "Dataset: OECD-FAO Agricultural Outlook" (various editions) [Online]. Available: https://stats.oecd.org [Accessed between October 2018 and February 2020].

[32] OECD/Food and Agriculture Organization of the United Nations (2019) "Statistical Annex", in OECD-FAO Agricultural Outlook 2019-2028, OECD Publishing, Paris/Food and Agriculture Organization of the United Nations, Rome. DOI 10.1787/93034453-en.

[33] OECD/Food and Agriculture Organization of the United Nations (2009) "Annex C: World Prices and Projections", in OECD-FAO Agricultural Outlook 2009, OECD Publishing, Paris. DOI 10.1787/agr_outlook-2009-16-en.

[34] OECD/Food and Agriculture Organization of the United Nations (2010) "Annex A. Statistical Tables", in OECD-FAO Agricultural Outlook 2010, OECD Publishing, Paris. DOI 10.1787/agr_outlook-2010-13-en.

[35] OECD/Food and Agriculture Organization of the United Nations (2011) "Statistical tables: Overview", in OECD-FAO Agricultural Outlook 2011, OECD Publishing, Paris. DOI 10.1787/agr_outlook-2011-6-en.

[36] OECD/Food and Agriculture Organization of the United Nations (2012) "Statistical Annex", in OECD-FAO Agricultural Outlook 2012, OECD Publishing, Paris. DOI 10.1787/agr_outlook-2012-15-en.

[37] OECD/Food and Agriculture Organization of the United Nations (2013) "Table A.2 - World prices", in OECD-FAO Agricultural Outlook 2013, OECD Publishing, Paris. DOI 10.1787/agr_outlook-2013-table164-en.

[38] OECD/Food and Agriculture Organization of the United Nations (2014) "World prices", in OECD-FAO Agricultural Outlook 2014, OECD Publishing, Paris. DOI 10.1787/agr_outlook-2014-table143-en.

[39] OECD/FAO (2020) "Table C.11 - World prices", in OECD-FAO Agricultural Outlook 2020-2029, OECD Publishing, Paris. DOI 10.1787/d45a7727-en.

[40] Pérez, D. I., Jensen, H., Philipidis, G., Fellmann, T., Chatzopoulos, T. and Gómez, B. M. (2018) "EU commodity market development: Medium-term agricultural outlook", Publications Office of the European Union. ISBN 978-92-79-97850-0. DOI 10.2760/4519. 